American Journal of Engineering and Applied Sciences 7 (1): 12-22, 2014

ISSN: 1941-7020

(C) 2014 T. Abu-Lebdeh et al., This open access article is distributed under a Creative Commons Attribution

(CC-BY) 3.0 license

doi:10.3844/ajeassp.2014.12.22 Published Online 7 (1) 2014 (http://www.thescipub.com/ajeas.toc)

\title{
THERMAL CONDUCTIVITY OF RUBBERIZED GYPSUM BOARD
}

\author{
Taher Abu-Lebdeh, Ellie Fini and Ashraf Fadiel
}

Department of Civil, Architectural and Environmental Engineering,

North Carolina A and T State University, NC 27411, Greensboro, USA

Received 2014-01-28; Revised 2014-02-13; Accepted 2014-03-14

\begin{abstract}
The disposal of scrap tires is a challenging task and hence an innovative solution to meet these challenges is needed. Extensive work has been done on the utilization of waste tires in a variety of applications in asphalt pavements and concrete. However, previous investigations focus only on the mechanical properties of the rubberized materials, but few on the thermal performance. This is especially true for rubberized gypsum. Limited or no experimental data on the thermal performance of rubberized gypsum board are available. In this study, an experimental program is established to investigate the effect of amount and size of crumb rubber on the thermal properties of gypsum materials. Gypsum is replaced by four different percentage of crumb rubber: $10,20,30$ and $40 \%$ by weight of gypsum and two sizes of crumb rubber (\#30,\#10_20) to make eight rubberized gypsum specimens. The prepared specimens were tested for thermal conductivity using an apparatus specially designed and constructed for this purpose. The experimental program was concluded by proposing an empirical equation to predict the thermal conductivity of rubberized gypsum board. Results indicated better thermal performance of the gypsum board due to the addition of crumb rubber. Thermal conductivity of the rubberized gypsum was 18-38\% lower than the ordinary gypsum. It is concluded that thermal conductivity of rubberized gypsum decreases with the increase of crumb rubber regardless the size of the rubber and that thermal conductivity of mixtures contained $40 \%$ of rubber was about 38\% lower than conventional mixture when crumb rubber \#10_20 was added, while the thermal conductivity reduced by $22 \%$ when crumb rubber \#30 was added. The study suggested for future work to investigate the effect of air voids size and ratio on the thermal conductivity of rubberized gypsum.
\end{abstract}

Keywords: Gypsum Board, Crumb Rubber, TPS Device, Construction Materials, Thermal Conductivity

\section{INTRODUCTION}

The significant increase in world energy consumption coupled with the growing demand for low emission sources of energy, creates an urgent need for efficient energy savings in buildings. In the US, Commercial and residential buildings are responsible for $38 \%$ of carbon dioxide emissions, $40 \%$ of non-industrial waste, $71 \%$ of electricity consumption and $39 \%$ of energy use. $14 \%$ of the energy consumption in building is due to lighting, $39 \%$ due HVAC and $47 \%$ other uses. Thus, green building technologies that focus on the production of efficient energy is needed. An economical viable solution to the energy and environmental concerns should include the utilization of waste materials for new products which minimize the heavy burden on the nation's landfills. Recycling of waste materials saves natural resources, saves energy, reduces solid waste, reduces air and water pollutants and reduces greenhouse gases. Bolden et al. (2013) investigated the effective use of recycled and waste materials in various construction applications. They connected researches and industry with an overview of what recycled materials are available for different applications and recommended North Carolina A and T State University, NC 27411, Greensboro, USA Tel: (336) 285-3670 Fax: (336) 334-7126 
better documentations for the green infrastructures benefits. Several other researchers from NC A\&T State University James et al. (2011); Ellie et al. (2011); Abu-Lebdeh et al. (2010a; 2010b); Fini and Abu-Lebdeh (2011) and Hamoush et al. (2011) and other governmental and academia agencies investigated several green materials technologies that reduce environmental effects and use recycled materials in infrastructures applications. The researchers developed several green material technology programs which maintain or improve current practices in construction engineering and ensures green products or methods arising from these programs that would be cost effective and would confer benefits on society, the economy and the environment.

Motivated by the trend toward green buildings and to reduce the effect of scrap tires on the environment and human health, the authors are currently working on several projects to find a practical and environmentally sound solution of the problem of scrap tires by developing a light weight with low thermal conductivity composite construction materials using waste tires. Landfills all over the world are filled with tremendous amounts of scrap tires. There are two billion scrap tires in the U.S. landfills with over 250 million tires added every year. These stockpiles are dangerous not only due to potential environmental threat, but also from fire hazards and provide breeding grounds for rats, mice and mosquitoes. One strategy to utilize waste tires in construction materials is to mechanically reduce them to crumb and subsequently combine the crumb with other materials to form a composite. For instance, Fini et al. (2013) investigated the feasibility of the application of scrap tire and swine manure to produce a sustainable alternative for bituminous asphalt used in pavement construction and Benazzouk et al. (2007) studied the effect of powdered tire rubber as an addition to the cement paste on both the physico-mechanical and water absorption properties. Further, extensive studies have been conducted on the use of waste tire modified Portland cement concrete in highway construction. However, almost most of the previous investigations on the re-use of tire rubber in cement-based materials focus only on the mechanical properties of the rubberized concrete. Overall results have indicated that rubberized concrete mixtures posses lower density, increased toughness and ductility, higher impact resistance, better sound insulation and decrease in compressive strength and splitting tensile strengths. The reduction in strength may be due to the weak bond between the cement paste and the rubber aggregates causing reduction in overall strength of the matrix. But, the loss may be minimized by prior surface treatment of the rubber particles.
Although, extensive work has been done on the mechanical properties of crumb rubber-cement composite, limited or no work has been previously reported on the thermal conductivity. This is especially true for rubberized gypsum.

This research project is an attempt to develop low thermal conductivity of rubberized gypsum boards using waste tires to help solve simultaneously energy and environment concerns by reducing heat transfer into building and recycle rubber tires. In this study, an experimental test program was conducted mainly to investigate the effect of incorporating crumb rubber particles on the thermal conductivity of gypsum board composite. A Sodium Hydroxide $(\mathrm{NaOH})$ solution was used as surface treatments to the crumb rubber.

\section{EXPERIMENTAL PROGRAM}

In this study, an experimental program was developed to study the effect of crumb rubber addition on the thermal conductivity of gypsum boards. Raw gypsum material was mixed with four different ratios $10 \%-40 \%$ and two sizes of crumb rubber. The mixture of each percentage level contains two sizes of crumb rubber, namely, \#10_20,\#30. A total of eight rubberized and one control specimens were prepared and tested for unit weight and thermal behavior. A heat transfer measurement device was designed and constructed according to the standards to measure thermal conductivity of the rubberized specimens.

\subsection{Materials}

Crumb rubber: The crumb rubber used in this study was provided by Liberty Tire Recycling Company. The crumb rubber was derived from used tires. Two different sizes of crumb rubber were used, namely, mesh 30 and mesh 10 to 20 . Mesh 30 or (\#30) was very fine powder rubber with size ranges from 0.01-0.6 mm and mesh 10 to 20 (\# 10-20) was coarse rubber with size ranges from 0.84 to $2 \mathrm{~mm}$ (Fig. 1). The specific gravity, density and sieve analysis of the two crumb rubber sizes and the combination of both sizes (\#30 and \#10_20) were tested and shown in Table 1 and Fig. 2.

Specific gravity and density of crumb rubber listed in Table 1 are the averages of three readings. As shown in Fig. 2, crumb rubber \#30 and \#10_20 had a consistent gradation and it was close to upper and lower limits of the gradation of fine aggregate, while the mixed crumb rubber (used in other tests and not herein) fill between the limits of the fine aggregate specification. 


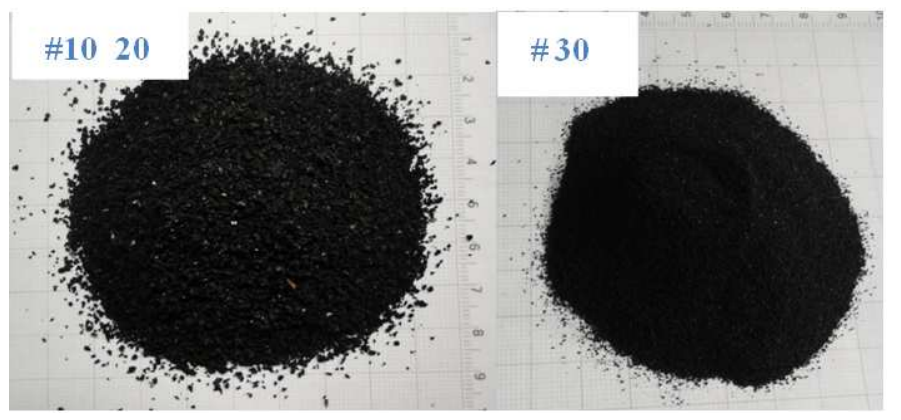

Fig. 1. Crumb rubber \#10_20 and \#30

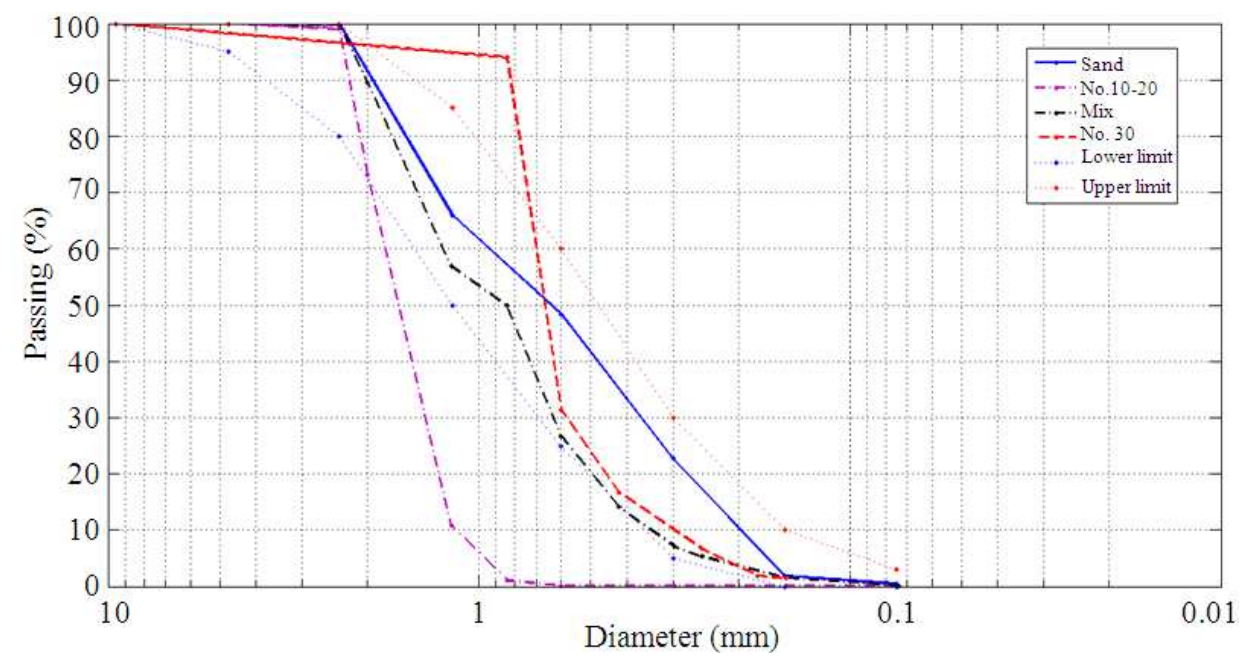

Fig. 2. Gradation of fine aggregate and crumb rubber

Table 1. Properties of crumb rubber

\begin{tabular}{lcrr}
\hline & Crumb rubber size & \\
& \multicolumn{1}{c}{-\#30 } & \multicolumn{1}{c}{ Mix } & \#10_20 \\
\hline Property & \multicolumn{1}{c}{ \#30.51 } & 0.59 & 0.78 \\
Density $\left(\mathrm{kg} / \mathrm{m}^{3}\right)$ & 445.00 & 436.00 & 421.00 \\
Fineness modulus & 2.42 & 3.08 & 3.84 \\
\hline
\end{tabular}

\subsection{Surface Treatment of Crumb Rubber}

Crumb rubber was surface treated with $10 \%$ concentrated Sodium Hydroxide solution $(\mathrm{NaOH})$. The rubber was first immersed for $20 \mathrm{~min}$ in $\mathrm{NaOH}$ solution. The next step was to sieve the rubber in sieve No.200, washed with clean water and filtered again and dried at ambient temperature. The $\mathrm{NaOH}$ treatment and water wash helped clean the rubber crumb from any foreign materials that might be attached to the rubber particles.

\subsection{Specimen Preparation}

In order to investigate the effect of crumb rubber inclusion into gypsum, rubberized gypsum was developed by partially replacing gypsum with crumb rubber. Gypsum was mixed with crumb rubber at four levels of replacement 10, 20, 30 and $40 \%$. At each level of replacement a portion of gypsum was replaced by weight with crumb rubber, while water to gypsum mass ratio of 0.35 kept constant. A specimen made of conventional raw gypsum material and eight specimens of rubberized gypsum were prepared and tested for unit weight and thermal conductivity tests. Mix ID and description of specimens are listed in Table 2.

\subsection{Mixing and Preparing Specimens}

The gypsum and crumb rubber were dry mixed for 1-2 min, then water was added to the mix. Then the mix was poured into molds with the size of $304.8 \times 304.8 \times 25.4 \mathrm{~mm}$ and finished with steel trowel. The specimens were demolded after $24 \mathrm{~h}$ and kept at ambient temperature until the testing day. Figure 3 shows the appearance of the rubberized gypsum specimens. 


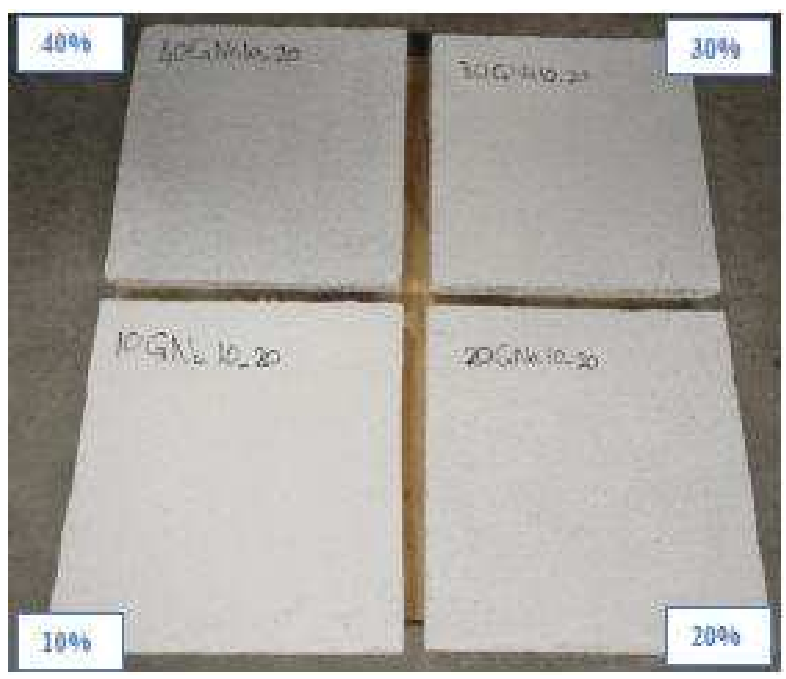

Fig. 3. Photographs of gypsum specimens

Table 2. Mix ID and description of specimens

\begin{tabular}{ll}
\hline Mix ID & Description \\
\hline PG & Plain gypsum \\
$10 \mathrm{G} \# 30$ & $10 \%$ of gypsum replaced with \#30 \\
$20 \mathrm{G} \# 30$ & $20 \%$ of gypsum replaced with \#30 \\
30G\#30 & $30 \%$ of gypsum replaced with \#30 \\
40G\#30 & $40 \%$ of gypsum replaced with \#30 \\
10G\#10_20 & $10 \%$ of gypsum replaced with \#10_20 \\
20G\#10_20 & $20 \%$ of gypsum replaced with \#10_20 \\
30G\#10_20 & 30\% of gypsum replaced with \#10_20 \\
40G\#10_20 & 40\% of gypsum replaced with \#10_20 \\
\hline
\end{tabular}

\section{TEST PROCEDURES}

\subsection{Thermal Conductivity of Crumb Rubber}

The thermal conductivity of crumb rubber was experimentally measured using Transient Plane Source (TPS) method following Horai and Simmons (1969) technique. In TPS method (Fig. 4), the source of heat is a hot disc which also serves as a temperature sensor. The TPS technique can measure solids and liquids with thermal conductivities ranging from 0.02 to $200 \mathrm{~W} / \mathrm{mK}$. In fact, this technique has already been used to estimate the thermal conductivity of different types of composites. In this method, the solid particles are mixed with a liquid and then the thermal conductivity of the saturated mixture is measured. The thermal conductivity of the solid particles is thus evaluated using the arithmetic mean.

In this study, the crumb rubber was mixed with glycerol and the TPS sensor was positioned between two layers of saturated mixes. In order to ensure a good thermal contact between the TPS sensor and the sample material, a chucking device was used. The thermal conductivity of pure glycerol liquid was determined first followed by the determinations of the thermal conductivity of the glycerol-rubber particle saturated mixture. The thermal conductivity of crumb rubber particles was evaluated by substituting the conductivities of the mixture and pure glycerol in the arithmetic mean expression provided by Horai and Simmons (1969). The thermal conductivity was measured three times and the mean values are reported.

\subsection{Unit Weight of Rubberized Gypsum}

The unit weight of the fresh rubberized gypsum was obtained in accordance with ASTM C642-06.

\subsection{Thermal Conductivity Measurement}

A specially designed thermal conductivity measurements device was constructed based on hot box apparatus. The principle of measurement is to place the specimen between two boundaries held at constant temperatures. One side was heated by a heat source and the other side was kept at room temperature. The box was constructed from homogeneous materials that have stable thermal properties and have high thermal resistance and good mechanical properties. The structure of the box shown in Fig. 5 was $113 \mathrm{~cm}$ height, $40.64 \mathrm{~cm}$ width and $40.64 \mathrm{~cm}$ deep $\left(44 \frac{1}{2} \times 16 \times 16\right.$ in.). The thickness of the surrounding chamber was $5.08 \mathrm{~cm}$ (2 in.). In order to minimize heat losses to its surroundings, the chamber was constructed of Extruded Polystyrene (XPS) layer placed between two layers of Maple plywood with a thickness of $0.635 \mathrm{~cm}(1 / 4 \mathrm{in}$.) each. The three layers were assembled using a heavy duty construction adhesive.

To measure heat flux, the device was equipped with HFP01 heat flux sensors (Fig. 6a). The body of HFP01 was composed of ceramics-plastic and a thermopile embedded in the plastic ceramic composite (thermopile is a set of connected thermocouples that can measure a small quantity of heat flux). To collect the data from HFP01, an accurate voltmeter that has millivolt range was used. HFP01 sensor was calibrated using a guarded hot plate according to ASTM C 177. It has sensitivity (E) of 61.37 $\mu \mathrm{V} / \mathrm{W} / \mathrm{m}^{2}$. After the voltage output was collected, the heat flux was calculated based on the following formula:

$\mathrm{Q}=\mathrm{V} / \mathrm{E}$

Where:

$\mathrm{Q}=$ Heat flux $\mathrm{W} / \mathrm{m}^{2}$

$\mathrm{V}=$ Measured voltage and

$\mathrm{E}=$ Sensor sensitivity $\left(61.37 \mu \mathrm{V} / \mathrm{W} / \mathrm{m}^{2}\right)$ 


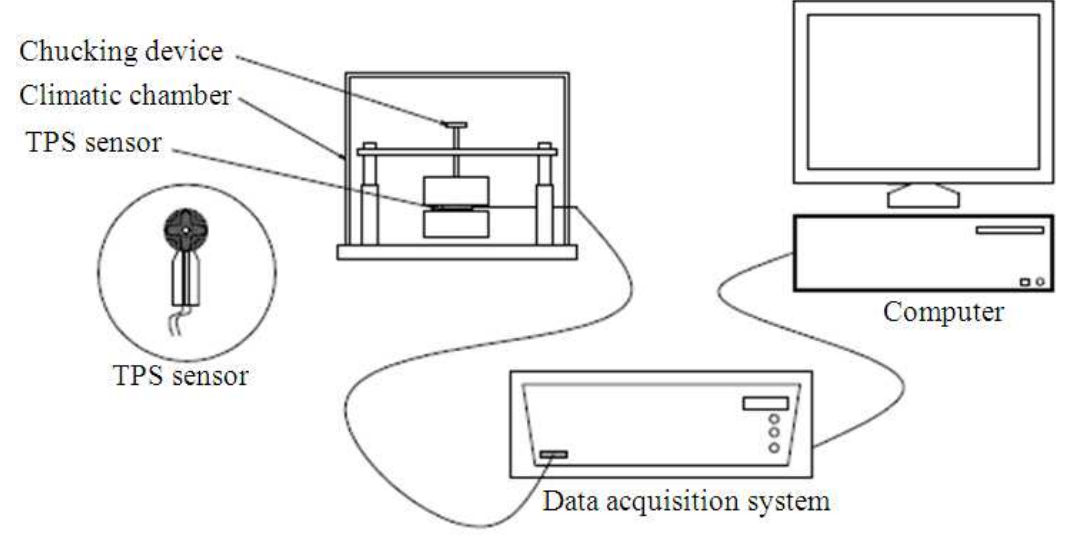

Fig. 4. Experimental TPS set-up

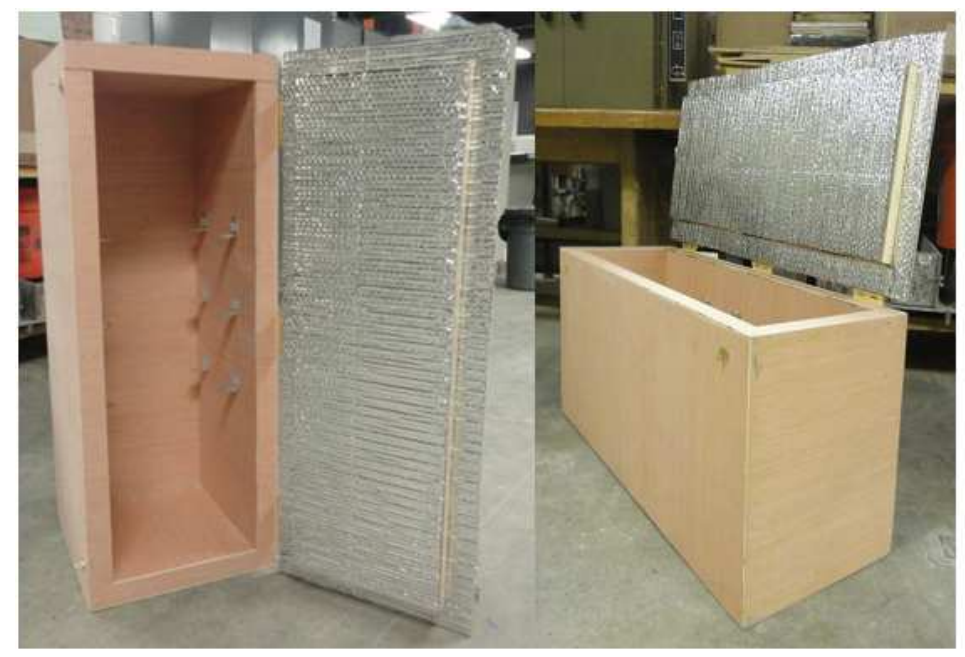

Fig. 5. Adiabatic box photographs

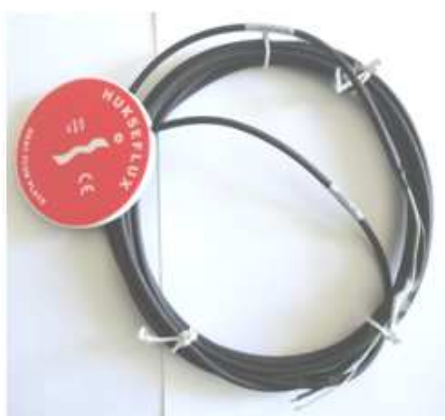

(a)

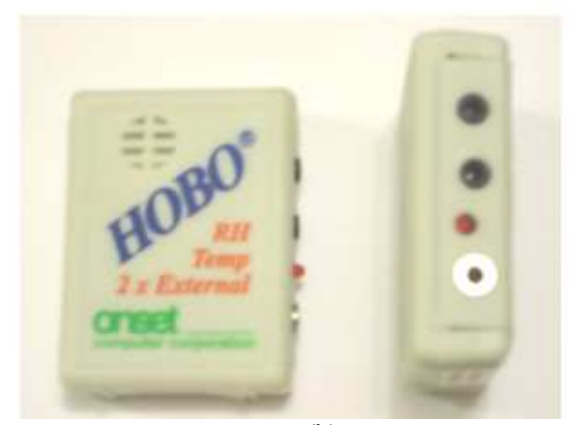

(b)

Fig. 6. (a) HFP01 heat flux sensor, (b) data logger

To measure temperature differences across the specimen, three temperature data loggers are placed from each side of the specimen. HOBO data logger type H08007-02 and box car 3.7 Software were used to measure 
temperature (Fig. 6b). The data logger has two internal temperature sensors and two external sensors. Further, the data logger is programmable in term of time increment and the start and end time.

\subsection{Calibration of the Measurement Device}

The device was calibrated by testing materials with known thermal conductivity. Four different construction materials were tested for thermal conductivity. The dimensions of the samples were $30.48 \times 30.48 \times 2.54 \mathrm{~cm}$ $(12 \times 12 \times 1$ in. $)$. The samples include: Gypsum board (drywall) with $1.27 \mathrm{~cm} \mathrm{(1/2} \mathrm{in.)} \mathrm{thick;} \mathrm{Oriented} \mathrm{Strand}$ Board (OSB) with $1.27 \mathrm{~cm}(1 / 2$ in.) thick; Plywood with $1.27 \mathrm{~cm}(1 / 2$ in.) thick; Mortar with $2.54 \mathrm{~cm}$ (1 in.) thick.

\subsection{Test Setup}

A schematic of thermal conductivity test setup is shown in Fig. 7.

The following testing steps were followed for each test: (a) Specimen was mounted and sealed from all sides; (b) The heat flux sensor was attached to the surface of the specimen with the red side facing the heat source (Fig. 8) and Heat flux was recorded when it reached steady state; (c) Three temperature loggers were mounted to each side of the specimen using double sided tape. The temperature logger was placed in such way that there was a temperature logger placed across from it on the other side; (d) the door of the box was tightly closed and sealed to ensure no heat loss through the edges of the door; (e) turn on the heat source: To reach steady state heat flow, the test was run for an hour and a half; (f) at the end of the test, the data were collected and the thermal conductivity was calculated using Fourier's law (Equation 2):

$\mathrm{Q}=-\mathrm{k} \frac{\Delta \mathrm{T}}{\mathrm{x}}$

Where:

$\mathrm{Q}=$ Heat flux $\mathrm{W} / \mathrm{m}^{2}\left(\mathrm{But} / \mathrm{hr}-\mathrm{ft}^{2}\right)$

$\Delta \mathrm{T}=$ Temperature difference across material section $\mathrm{K}$ or ${ }^{\circ} \mathrm{C}\left({ }^{\circ} \mathrm{F}\right)$,

$\mathrm{x}=$ Material thickness $\mathrm{m}(\mathrm{ft})$ and

$\mathrm{k}=$ Thermal conductivity $\mathrm{W} / \mathrm{m} . \mathrm{k}(\mathrm{Btu} / \mathrm{h}-\mathrm{ft}-\mathrm{F})$

The device was calibrated by conducting the test on materials with known thermal conductivities. The data of theses reference materials were obtained from online sources (www.engineeringtoolbox.com and www.bca.gov.sg) and from engineering handbooks. The thermal conductivity of the reference materials along with the results are shown in Fig. 9 and listed in Table 3.

A statistical analysis was carried out to determine a correction factor. The statistical analysis yielded an $\mathrm{R}^{2}$ value of 0.995 which indicated a strong relation between the reference and experimental values. Using the statistical analysis, an equation was derived (Equation 3) to modify the experimental values, the equation may be expressed as:

$\mathrm{k}_{\mathrm{m}}=0.964 \mathrm{k}_{\text {exp }} \cdot+0.011$

Where:

$\mathrm{k}_{\mathrm{m}}=$ Modified thermal conductivity value and

$\mathrm{k}_{\mathrm{exp}}=$ Experimental thermal conductivity value

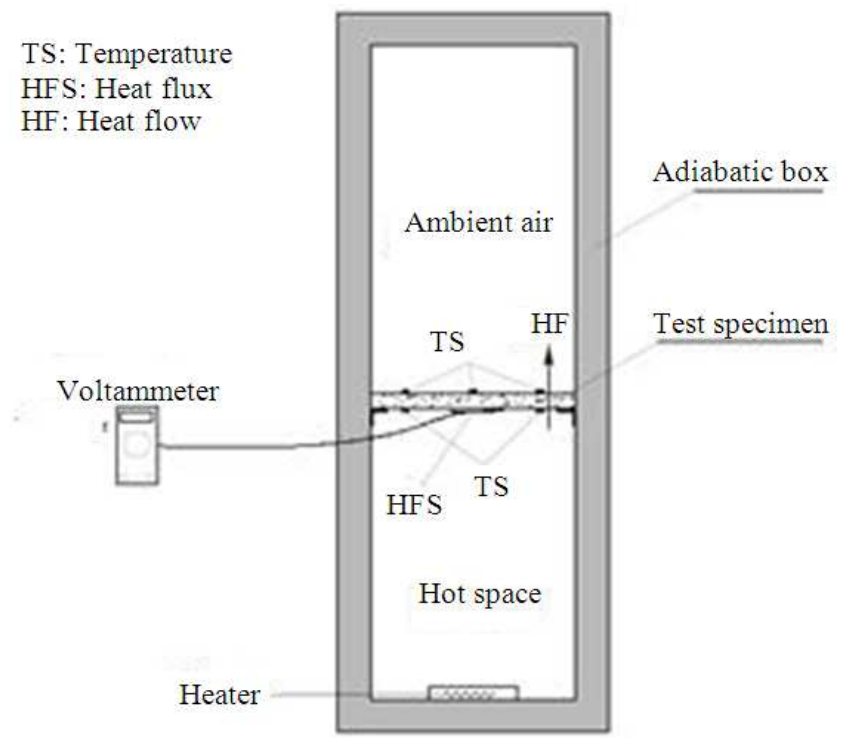

Fig. 7. Schematic of the test set-up 
Taher Abu-Lebdeh et al. / American Journal of Engineering and Applied Science 7 (1): 12-22, 2014

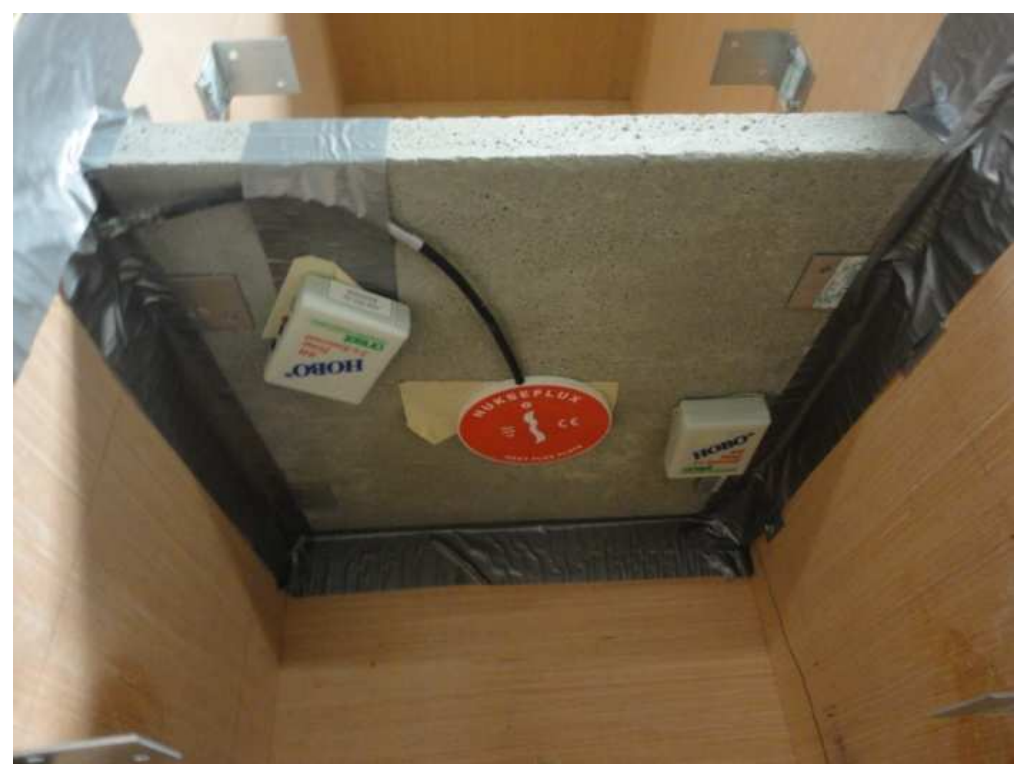

Fig. 8. Heat flux and temperature loggers attached to the specimen

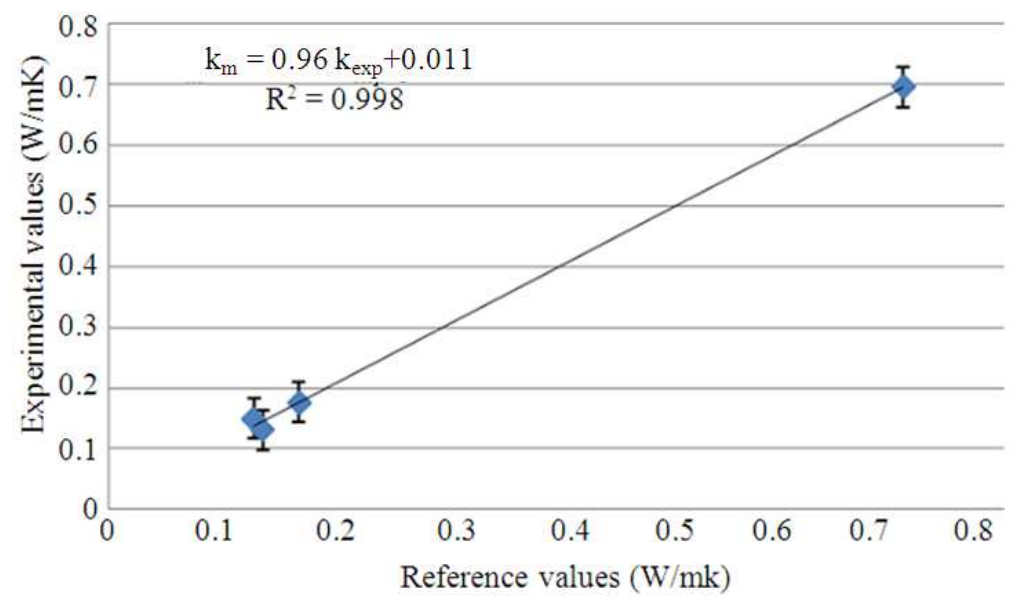

Fig. 9. Experimental Vs. reference values

Table 3. Experimental versus reference values

\section{Conductivity (W/mK)}

Sample designation

Reference values

Test values

Gypsum board, $1 / 2$ in thick

0.170

0.1760

Gypsum board, $1 / 2$ in. thick

Gypsum board, $1 / 2$ in. thick

Oriented strand board, $1 / 2$ in.

0.170

0.1720

0.170

0.1790

Plywood with $1 / 2$ in. thick

0.130

0.1495

Mortar, $2.54 \mathrm{~cm}$ (1 in.) thick

0.138

0.1304

Mortar, $2.54 \mathrm{~cm}$ (1 in.) thick

Mortar, $2.54 \mathrm{~cm}$ (1 in.) thick

0.710

0.6820

0.710

0.6720

0.710

0.7340 


\section{EXPERIMNETAL RESULTS}

Generally, all mixtures of rubberized gypsum exhibited a lower unit weight compared to the plain gypsum which indicates that lightweight construction materials can be obtained by incorporating waste tire materials (crumb rubber) into mix ingredients. Further, an improvement of the specimen's thermal property was achieved and that can be seen by the reduction in the thermal conductivity of mixtures containing crumb rubber.

\subsection{Thermal Conductivity of Crumb Rubber}

The thermal conductivity of crumb rubber particles was experimentally measured using the TPS method described above. The average value of the thermal conductivity of rubber particles was found to be around $0.187 \mathrm{~W} / \mathrm{mK}$.

\subsection{Density of Rubberized Gypsum}

Depending on the amount and the size of crumb rubber, the density of rubberized gypsum was found to be less than that of plain gypsum (Fig. 10). The density decreases when the amount of crumb rubber increases regardless of the size of the rubber particles. When $40 \%$ of gypsum was replaced with crumb rubber \#30 and \#10_20, the density decreases by 20 and $12 \%$, respectively. The decrease in the density was more pronounced in mixtures contained \#30 crumb rubber. For example, the density decreases by $8.5 \%$ when mixture contained $20 \%$ of \#30 compared to mixture contained $30 \%$ of \#30, while this decrease was only $3.5 \%$ for mixtures contained \#10_20 crumb rubber. This suggests that finer size of crumb rubber (\#30) had a slightly higher effect on the reduction of the density than the coarser size (\#10_20).

\subsection{Thermal Conductivity of Rubberized Gypsum}

The thermal conductivity of the rubberized gypsum varied depending on the amount and size of crumb rubber. The findings of this study, shown in Fig. 11 and tabulated in Table 4, show that the thermal conductivity decreased when the amount of rubber increased regardless the size of crumb rubber. A reduction of 22.1 and $38.4 \%$ was observed when $40 \%$ of gypsum was replaced with crumb rubber \#30 and \#10_20 with respect to the plain gypsum mixture. The size of crumb rubber also had an effect on the thermal conductivity of rubberized gypsum. A higher reduction of $\mathrm{k}$-values was observed when coarser size was incorporated into gypsum mixture. The thermal onductivty of rubberized gypsum range from $0.187-0.248 \mathrm{~W} / \mathrm{mK}$ and that about $18-38 \%$ lower than the control mixture. The thermal conductivity of all rubberized gypsum mixtures contained \#10_20 were lower than that of mixtures comtained \#30. For mixtures contained crumb rubber \#30, the improvement of the thermal resistance of the mixtures was about $2 \%$ from level of replacement to the next. For example, the thermal values of mixture contained 20 was $2 \%$ lower than that of mixture contained $10 \%$. On the other hand, the reduction in thermal conductivity of mixture contained \#10_20 crumb rubber was more manifest. From 10 to $20 \%$ rubber addition, thermal conductivity decreased by $2 \%$. This was increased to about $4 \%$ when the amount of rubber increased from 20 to $30 \%$. Finally, when rubber amount increased to $40 \%$, there was about $13 \%$ decrease in the thermal conductivity. This suggests an improvement in the thermal resistance due to the increase in rubber content.

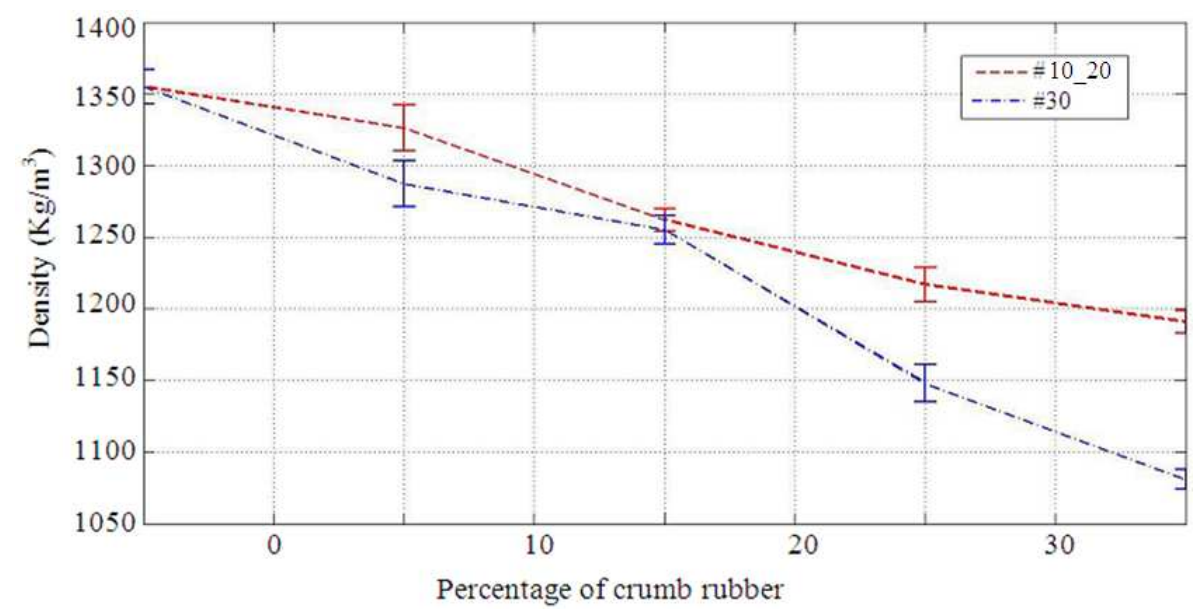

Fig. 10. Density of rubberized gypsum 


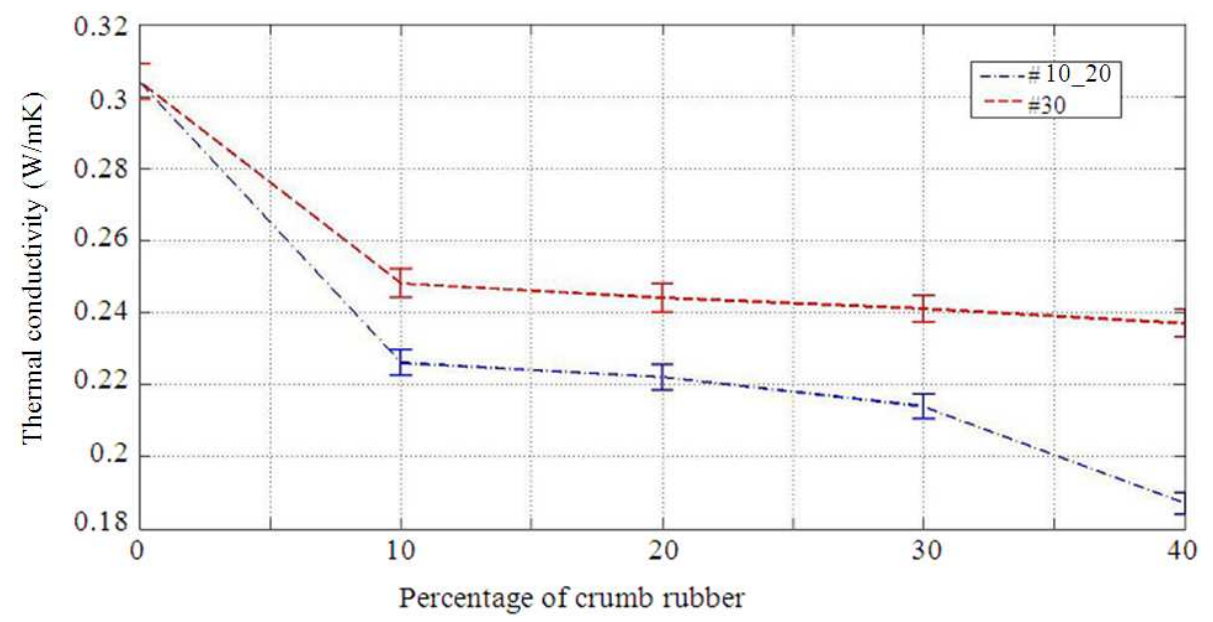

Fig. 11. $k$ Vs. amount and size of crumb rubber

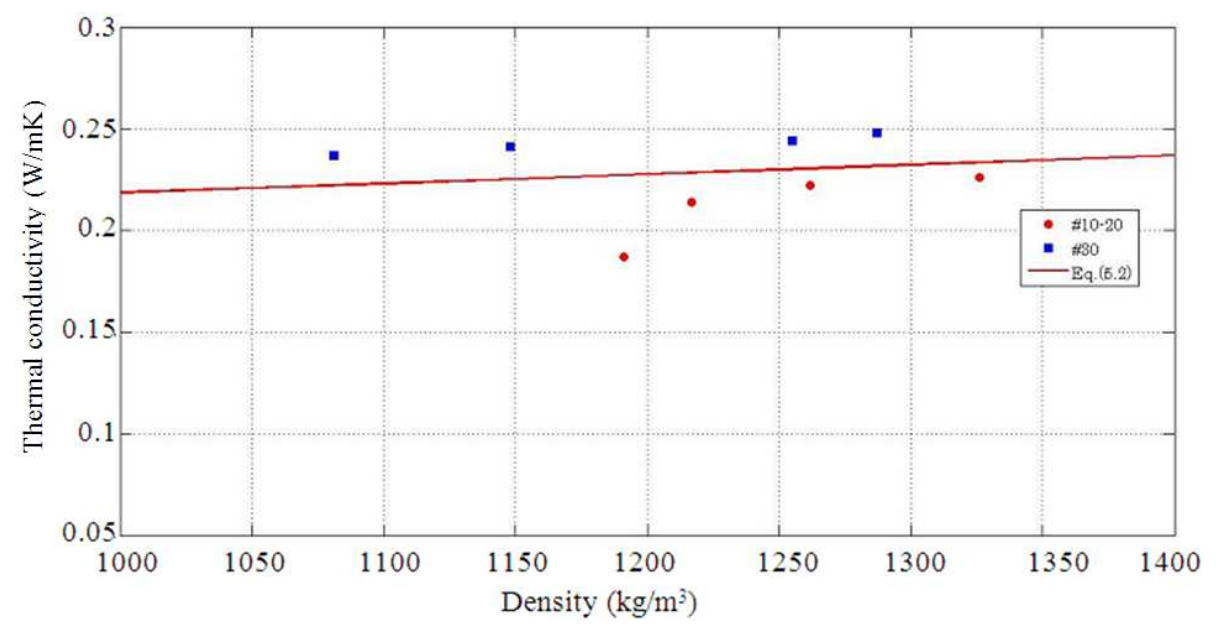

Fig. 12. Experimental Vs. empirical results of rubberized gypsum

Table 4. Thermal conductivity of rubberized gypsum

\begin{tabular}{llc}
\hline Mixture ID & k-value $(\mathrm{W} / \mathrm{mK})$ & \% Reduction \\
\hline PM & 0.304 & 0.0 \\
10G\#30 & 0.248 & 18.4 \\
20G\#30 & 0.244 & 19.9 \\
30G\#30 & 0.241 & 20.7 \\
40G\#30 & 0.237 & 22.1 \\
10G\#10-20 & 0.226 & 25.6 \\
20G\#10-20 & 0.222 & 27.1 \\
30G\#10-20 & 0.214 & 29.6 \\
40G\#10-20 & 0.187 & 38.4 \\
\hline
\end{tabular}

\section{EMPIRICAL RELATIONSHIP}

An empirical equation was derived to predict the thermal conductivity of rubberized gypsum. Equation 4 was derived based on relation between the thermal conductivity and density of rubberized gypsum:

$\mathrm{k}=0.179 \mathrm{e}^{0.0002 \rho}$

Where:

$\mathrm{k}=$ Thermal conductivity $(\mathrm{W} / \mathrm{mK})$ and

$\rho=$ Density of rubberized gypsum $\left(\mathrm{kg} / \mathrm{m}^{3}\right)$

A comparison between experimental values and corresponding values obtained from Equation 4 is displayed in Fig. 12. The error range between the experimental and theoretical values as listed in Table $\mathbf{5}$. The range of error varied from 3 to $21 \%$. However, $21 \%$ error was corresponded to one value and if this value was discarded the range of error would be reduced to $3-7 \%$. 
Table 5. Experimental versus theoretical k-values

\begin{tabular}{lllr}
\hline & \multicolumn{2}{c}{ Thermal conductivity } & \\
Mix ID & Experimental & Theoretical & \% Error \\
\hline 10G\#10-20 & 0.226 & 0.233 & -3 \\
20G\#10-20 & 0.222 & 0.230 & -4 \\
30G\#10-20 & 0.214 & 0.228 & -7 \\
40G\#10-20 & 0.187 & 0.227 & -21 \\
10G\#30 & 0.248 & 0.232 & 7 \\
20G\#30 & 0.244 & 0.230 & 6 \\
30G\#30 & 0.241 & 0.225 & 7 \\
40G\#30 & 0.237 & 0.222 & 6 \\
\hline
\end{tabular}

\section{DISCUSSION}

In this study, the thermal conductivity of pure crumb rubber particles was measured using Transient Plane Source (TPS) technique. A disk-shaped TPS-element was placed between two glycerol-based rubber particle mixtures. The average value of the thermal conductivity of rubber particles was determined and found to be around $0.187 \mathrm{~W} / \mathrm{mK}$.

The thermal conductivity of the rubberized gypsum composite was determined using a specially designed and constructed thermal conductivity measurements device based on hot box apparatus. The $\mathrm{k}$ - value was obtained by taking the averages of heat flux passing through the specimen at steady state condition and temperature difference across the specimen concurrently. These values were used in the Fourier's law (Equation 2) to calculate the $\mathrm{k}$ - values. The results were then modified using Equation 3 which was established by comparing the $\mathrm{k}$ - value of known materials by k-values obtained for the same materials using the designed apparatus. Experimental results obtained herein show that thermal conductivity of the rubberized gypsum deceases when the amount of rubber increases regardless of the size of the crumb rubber. The decrease in thermal conductivity of gypsum contained rubber can be related to two factors, the increase in air content and low thermal conductivity of rubber compared to the raw gypsum. Findings show that the thermal onductivty of rubberized gypsum range from $0.187-0.248 \mathrm{~W} / \mathrm{mK}$ which represents about $18-38 \%$ lower than the control mixture. The thermal conductivity of all rubberized gypsum mixtures contained \#10_20 were lower than that of mixtures comtained \#30.

It should be mentioned that Sodium Hydroxide $(\mathrm{NaOH})$ solution was used as rubber's surface treatment to increase its adhesion to gypsum and to enhance the hydrophilicity of the rubber surface. It is assumed that the $\mathrm{NaOH}$ hydrolyzes the acidic and carboxyl groups present on the tire rubber surface.

\section{CONCLUSION}

This research investigated the effect of crumb rubber on the thermal conductivity of the rubberized gypsum. The thermal conductivity was measured using a specially made device based on the principle of common measurement techniques. From the findings of the experimental work, the following conclusions may be drawn:

- The density of rubberized gypsum at $40 \%$ rubber inclusion reduced by $20 \%$ compared to the conventional gypsum mixture

- Rubberized gypsum mixtures contained crumb rubber particles \#30 had unit weight lower than mixtures contained crumb rubber particles \#10_20 at the same level of replacement

- Thermal conductivity decreased with rubber amount increased regardless the size of the rubber

- Thermal conductivity of mixtures contained $40 \%$ of rubber inclusion was about $38 \%$ lower than conventional mixture when crumb rubber \#10_20.while the thermal conductivity reduced by $22 \%$ when crumb rubber \#30 was added

- Rubberized gypsum can be used in drywalls since it showed a better thermal insulation performance than plain gypsum

- The reduction in the density and the thermal conductivity of rubberized gypsum can be utilized as lightweight coating material for interior usage to improve the thermal performance of walls

- Suggested future work include: (a) Study the effect of rubberized gypsum boards on the overall energy consumption of buildings and (b) investigate the effect of air voids size and air voids ratio on the thermal conductivity of rubberized mortar materials.

\section{REFERENCES}

Abu-Lebdeh, T., S. Hamoush, W. Heard and B. Zornig, 2010a. Effect of matrix strength on pullout behavior of steel fiber reinforced very-high strength concrete composites. Constr. Build. Mater. J., 25: 39-46. DOI: 10.1016/j.conbuildmat.2010.06.059

Abu-Lebdeh, T., S. Hamoush and B. Zornig, 2010b. Rate Effect on pullout behavior of steel fibers embedded in very-high strength concrete. Am. J. Eng. Applied Sci., 3: 454-463. DOI: 10.3844/ajeassp.2010.454.463 
Benazzouk, A.D., T. Langlet, K. Mezreb, J.M. Roucoult and M. Quéneudec, 2007. Physico-mechanical properties and water absorption of cement composite containing shredded rubber wastes. Cement Concrete Compos., 29: 732-740. DOI: 10.1016/j.cemconcomp.2007.07.001

Bolden, J., T. Abu-Lebdeh and E. Fini, 2013. Utilization of recycled and waste materials in various construction applications. Am. J. Environ. Sci., 9: 14-24. DOI: 10.3844/ajessp.2013.14.24

Ellie, H., I. Fini, L. Al-Qadi, T. Abu-Lebdeh and J.F. Masson, 2011. Use of surface energy to evaluate adhesion of bituminous crack sealants to aggregates. Am. J. Eng. Applied Sci., 4: 244-251. DOI: 10.3844/ajeassp.2011.244.251

Fini, E., D. Oldham and T. Abu-Lebdeh, 2013. Synthesis and Characterization of Bio-Modified Rubber (BMR) asphalt: A sustainable waste management solution for scrap tire and swine manure. J. Environ. Eng., 10.1061/(ASCE)EE.1943-7870.0000765
Fini, E. and T. Abu-Lebdeh, 2011. Bonding property of bituminous crack sealants in the presence of water. Am. J. Eng. Applied Sci., 4: 124-129. DOI: 10.3844/ajeassp.2011.124.129Ganjian, E.,

Hamoush, S., T. Abu-Lebdeh, M. Picornell and S. Amer, 2011. Development of sustainable engineered stone cladding for toughness, durability and energy conservation. Constr. Build. Mater., 25: 4006-4016. DOI: 10.1016/j.conbuildmat.2011.04.035

Horai, K. and G. Simmons, 1969. Thermal conductivity of rock-forming minerals. Earth Planetary Sci. Lett., 6: 359-368. DOI: 10.1016/0012-821X(69)90186-1

James, M.N., W. Choi and T. Abu-Lebdeh, 2011. Use of recycled aggregate and fly ash in concrete pavement. Am. J. Eng. Applied Sci., 4: 201-208. DOI: 10.3844/ajeassp.2011.201.208 